\title{
Four Paradigm Cases of Dependency in Care Relations
}

\author{
Simon van der Weele \\ University of Humanistic Studies, Citizenship and Humanisation of the Public Sector, Kromme \\ Nieuwegracht 29, Utrecht, 3512 HD Netherlands \\ Corresponding author. Email: s.vanderweele@uvh.nl
}

(Received 21 June 2019; revised 13 February 2020; accepted 21 February 2020)

\begin{abstract}
Dependency functions as a keyword in care theory. However, care theorists have spelled out the ontological and moral ramifications of dependency in different and often conflicting ways. In this article, I argue that conceptual disputes about dependency betray a fundamental discordance among authors, rooted in the empirical premises of their arguments. Hence, although authors appear to share a vocabulary of dependency, they are not writing about quite the same phenomenon. I seek to elucidate these differences by teasing out and comparing different conceptions of dependency found in the literature. Borrowing a phrase from Eva Kittay, I trace four "paradigm cases" of dependency: the infant, the physically disabled person, the profoundly intellectually disabled person, and the refugee. These paradigm cases serve as the empirical touchstone from which theorists extract their conceptions of dependency. Each paradigm case, moreover, permits (or even implores) a particular ethical sensibility toward care. How we understand and value dependency thus seems to determine how we understand and value care, and vice versa. In this way, I contend, our normative orientation toward care might influence what sorts of dependency we see-and, by extension, which forms of dependency we fail to notice.
\end{abstract}

[A] dependent stance is advantageous only if genuine-that is, if the putative dependent is truly incompetent... . I believe that the very structure of helping or caring relationships invites the marginalization of whoever is consigned to the position of dependence.

(Silvers 1995, 40)

When we acknowledge how dependence on another saves us from isolation and provides the connections to another that makes [sic] life worthwhile, we can start the process of embracing needed dependencies.

(Kittay 2011, 57)

\footnotetext{
(c) The Author(s), 2021. Published by Cambridge University Press on behalf of Hypatia, a Nonprofit Corporation. This is an Open Access article, distributed under the terms of the Creative Commons Attribution-NonCommercial-ShareAlike licence (http://creativecommons.org/licenses/by-nc-sa/4.0/), which permits non-commercial re-use, distribution, and reproduction in any medium, provided the same Creative Commons licence is included and the original work is properly cited. The written permission of Cambridge University Press must be obtained for commercial re-use.
} 
An unbearable or non-negotiable dependency nevertheless persists within the social bond that one requires for life... [T] here are forms of vulnerability and dependency that give rise to their own forms of aggression and destructiveness.

(Butler 2017)

These quotations introduce the central problem of this article. The term dependency figures prominently in each. Clearly, these authors have in common a vocabulary of dependency. They also share in their attempt to theorize the ontological and normative implications of this concept. However, each arrives at different conclusions. Anita Silvers speaks about being "consigned to the position of dependence," whereas Eva Kittay speaks of "needed dependencies"; Kittay calls for an embrace of dependency, but Judith Butler brings to the fore its unbearable character. How is it that these thinkers value dependency so differently? Why do they raise such different points about dependency's relationship to care? In short, I wish to raise the question: what or whom do these authors have in mind when they use the word dependency?

In what follows, I will claim that the differences among these authors are rooted in the empirical starting point of their respective arguments. Thus, despite their shared vocabulary of dependency, none of them is writing about quite the same phenomenon. Borrowing a phrase from Kittay, I will refer to these empirical touchstones as "paradigm cases" of dependency. I will trace four such paradigm cases in extant care-theoretical literature on dependency: the infant, the physically disabled person, the intellectually disabled person, and the refugee. ${ }^{1}$

Doing so will give rise to three interrelated claims: first, that different empirical touchstones lead different authors to conceptualize dependency differently, resulting in four distinct paradigm cases of dependency; second, that disagreements about dependency are best understood as a consequence of authors drawing on different paradigm cases; and third, that each paradigm case sensitizes authors to different aspects of dependency, leading them to adopt a particular ethical sensibility toward care-or, conversely, that a particular ethical sensibility toward care might lead authors to opt for a particular paradigm case. I will develop all three of these claims below.

\section{Locating the "Dependency Debate"}

Over the past few decades, dependency has surfaced as a key term in (often feminist) philosophical discussions of care (Collins 2015; Engster 2019). The proliferation of dependency as a core concept is particularly visible in (but not limited to) discussions in feminist theory, (critical) disability studies, bioethics, virtue ethics, and ethics of care. In addition, authors such as Martha Nussbaum have started to introduce the notion of dependency into frameworks of liberal philosophy as well (Nussbaum 2006). More recently, vulnerability and precarity have begun to enter into these discussions as related key terms. ${ }^{2}$ In many of these discussions, dependency is charged with both ontological and moral significance. However, though many authors share a reliance on the notion of dependency, their respective readings of dependency diverge widely. In this way, dependency has become the subject of much dispute.

Two points of contention stand out in particular. First is the question of the nature of dependency: here, authors debate whether dependency must be regarded as an ontological truth (Kittay 1999; Oliver 2002; Butler 2010), a socially constructed condition (Barnes 1991; Silvers 1995), a pattern of behavior (Baltes 1996), an attitude (Manschot 1994), a stigmatizing label (Fraser and Gordon 1994; Schram 2000), a psychological disposition (De Beaufort 2013), or some combination of these. Second is the question 
of the moral value of dependency: simplifying the discussion into its hyperbolic extremes, one could say that authors debate whether dependency ought to be embraced for enabling the virtue of care, or rather rejected and disavowed in order to prevent oppressive practices of care (Fine and Glendinning 2005). (In reality, most authors take a position somewhere between these extremes.)

Proponents of the various interpretations of dependency have entered into conversation with one another's work on various occasions (Silvers 1995; Morris 2001; Kittay 2011; Simplican 2015). Moreover, some authors have provided summaries of these discussions from a bird's-eye perspective, sketching the general stakes of the debate and the range of available positions, as well as possible ways to break theoretical impasses (Watson et al. 2004; Fine and Glendinning 2005; Hughes et al. 2005; Kröger 2009; Kelly 2013; Keyes, Webber, and Beveridge 2015; Winance, Damamme, and Fillion 2015; Winance 2016). Often, arguments in the "dependency debate" consist either in affirming the author's position by refuting another, or in proposing a way of transcending entrenched positions and proffering an integrated, synthesized concept of dependency instead. Although such conversations have garnered fruitful results, and many writers have recognized the value in recognizing at least interdependency as a universal social condition (Oliver 1989; Tronto 1993; Fine and Glendinning 2005; Butler 2010), the "dependency debate" has yet to abate-as evidenced by more recent work by Christine Kelly, Stacy Simplican, Rachel Adams, and Myriam Winance, Aurélie Damamme, and Emmanuelle Fillion (Kelly 2013; Simplican 2015; Adams 2017; and Winance, Damamme, and Fillion 2015). ${ }^{3}$

This article seeks to contribute to the "dependency debate" as well, although the argument will not follow the pattern of most of the works mentioned above. To endorse one particular position or to propose an integrated perspective would be to suggest that the "dependency debate" is essentially a resolvable conflict. I contend, to the contrary, that the conceptual and moral disputes over dependency betray a more fundamental discordance among authors, rooted in the empirical premises of their particular arguments. Put very simply, I suggest that many authors appear to share a vocabulary of dependency but are in fact not writing about quite the same phenomenon. This, in turn, leads them to distinct ethical sensibilities toward the matter of care, which cannot easily be aligned.

In order to arrive at these points, I will trace the various ways in which the word dependency has been employed to signify a particular condition or state of needing care or assistance. To do so, I find it helpful to speak of "paradigm cases" of dependency, a phrase I borrow from Kittay. In Love's Labor, Kittay introduces a paradigm case of dependency to get to the "pragmatic requirements" and "moral demands" of what she calls "dependency work." She takes as her paradigm case of dependency a situation of complete and unidirectional dependency, in which a "charge" is someone who is wholly dependent on the "dependency worker" for attaining "life-sustaining resources" (Kittay 1999, 31). Kittay presents her paradigm case as a hypothetical construct-a "limit case" essentially stripped from empirical reality, yet pliable enough to be applied to more concrete cases. It thus functions as a theoretical mold of sorts, which can be modified to fit the complexities of "real life," such as reciprocal caring and the sharing of care burdens (32). However, I contend here that her "paradigm case" in fact contains a clear empirical touchstone, one that greatly informs the shape her hypothetical construct takes, and that leads her to adopt a particular ethical sensibility. (This is her daughter Sesha, as we will see below.) It contains what Lolle Nauta has called an "exemplary situation" (Nauta 1984, 365), an empirical point of reference that informs 
philosophical thought and often (but not always) remains implicit (see also Mol 2008). My argument is that such an "exemplary situation" can be traced in other theoretical positions on dependency in care relations, too-each time resulting in a different conception of dependency itself. Hence, we can distinguish among more "paradigm cases" than the one put forward by Kittay. The aim of this article, then, is to demonstrate how various theories of dependency (including Kittay's) are in fact empirically charged; and that these diverging empirical touchstones result in conflicting conceptualizations of dependency itself, which bring the authors to divergent ethical sensibilities. ${ }^{4}$

So when I speak of paradigm cases of dependency, I speak (contra Kittay) of the empirical touchstone from which the authors in these fields extract their respective theories of dependency. In this article, I will discuss four such paradigm cases of dependency: the infant, the physically disabled person, the profoundly intellectually disabled person, and the refugee. I believe that at least one of these informs most philosophical accounts of dependency in care theory. ${ }^{5}$ Each of these paradigm cases takes the most salient features of a particular empirical example and abstracts these into a theoretical concept of dependency. In this way, each sheds light on different aspects of the ontological and ethical ramifications of dependency. Therefore, by teasing out these four paradigm cases we can begin to understand why the word dependency has been used to describe different and sometimes even contradictory circumstances of caring. It can help explain, for instance, why, in the quotations that open this article, Silvers, Kittay, and Butler use a similar vocabulary to make such different points. It is not necessarily that some get dependency right and others do not. It is rather that they are using the same word with a different referent in mind.

However, if the paradigm cases involve a degree of abstraction (and take only the most salient features of their empirical touchstone), this has implications for their respective depictions of dependency. Nauta notes of "exemplary situations" that they function as "a kind of model and a model not only opens up certain ways of seeing, but forecloses others as well" (Nauta 1984, 366). This suggests that the use of paradigm cases might illuminate some aspects of dependency, but also that it might serve to obfuscate others. I contend that although paradigm cases open up ample analytical space, each also comes with particular limitations-for instance, because the empirical example itself provides too narrow a window for conceptualizing dependency or because the empirical example is too narrowly (and normatively) construed on the basis of what are deemed to be its most salient characteristics. These limitations hint at the philosophical pitfalls of the paradigm cases-a point I will return to in the conclusion.

Before I begin the analysis proper, I wish to pose some caveats. First, tracing paradigm cases also means isolating them by focusing on finding a common element in distinctive and sophisticated pieces of writing. I want to stress at the outset that it is not my aim here to assess and interrogate particular authors who use a particular paradigm case, or to reduce the complexity of their positions to a single empirical example. After all, not all authors I discuss below make exclusive use of a single paradigm case. Nor do all authors use such a paradigm case explicitly (although many do). Rather, by grouping theorists together, I wish to highlight the tacit argumentative logic that, in my view, fuels the "dependency debate."

Second, my analysis involves a certain degree of backtracking to early writings on dependency and care, and as a result, traces not only paradigm cases but also (somewhat loosely) the historical development of a concept in care theory. Therefore, I busy myself in part with theoretical positions that have in more recent work been reworked and reconsidered by others (often, in fact, by having one paradigm case 
bear on another, as I will show). I will address these newer developments, but not always in one breath with the "early" work: I wish to describe the paradigm cases in their fundamentals before examining how they have been brought into dialogue.

Third and finally, I limit myself to discussing four paradigm cases of dependency in care relations. I believe that these are the most prevalent in and significant for care theory and that they provide the most distinctive theoretical contributions. No doubt one could trace other empirical examples of dependency in the literature-such as the elderly person or the network-but none are theorized as frequently or with the same robustness as the four I will discuss below. ${ }^{6}$

The next four sections of the article are devoted to describing four paradigm cases of dependency: the infant, the physically disabled person, the profoundly intellectually disabled person, and the refugee. I will list the basic premise of each, name the aspects of dependency they highlight (and risk downplaying), and situate each in its intellectual context. Afterwards, I will further analyze the logic of the paradigm cases in arguments about dependency and consider their philosophical limitations.

\section{The Infant}

The infant has figured prominently in care-ethical literature since its inception-indeed, many classic reflections on care, such as those by Nel Noddings, Sara Ruddick, and Virginia Held, center on the figure of the infant (Noddings 1984; Held 1993; Ruddick 1995). The paradigm case of the infant is in fact so widely used that it often appears in conjunction with the other paradigm cases outlined below. It is perhaps for this reason that Susan Dodds calls the infant "the archetype of human dependency" (Dodds 2014, 184).

Writers on dependency invoke the dependent infant to signify the universality of dependency and care in human life. The idea is that all of us were at some point infants in need of sustenance and affection. For example, Held relies on the paradigm case of the infant when she speaks of "the truly universal experience of care. Every human being has been cared for as a child or would not be alive" (Held 2006, 3). Joan Tronto, too, calls on this paradigm case in her assertion that "it is a part of the human condition that our autonomy occurs only after a long period of dependence" during childhood (Tronto 1993, 162). In these instances, the figure of the infant aligns dependency with the human condition, denoting that dependency is inevitable and universally shared. In this sense, the paradigm case of the infant needs to be considered as part of feminist attempts to destabilize the liberal conception of the autonomous individual subject-what Kittay called the "dependency critique" of liberalism (Kittay 1999, 13). The paradigm case of the infant thus serves to depict dependency as inevitable (because it is the starting point of every human life) and care as necessary (because children will not survive without a sustained caring effort).

In addition, the paradigm case of the infant also posits dependency as essentially temporary. As an ontological condition, dependency is universally shared, but each person grows out of it to become an adult (and person who cares) herself. One of the functions of care is to facilitate this transition. ${ }^{7}$ In this way, the infant helps to normatively anchor care to dependency: the suggestion is that dependency requires a response of care in order to make life possible, which frames care as a good in itself.

The paradigm case of the infant brings a number of aspects of dependency to the fore. First, by taking dependency as the starting point of every human life, the infant serves to make a case for the universality of dependency. Underscoring this fundamental condition of human life helps authors who seek to challenge various (for example, 
liberal) conceptions of autonomy and subjectivity. Extrapolating the paradigmatic dependency of infants to all human beings, the paradigm case of the infant has paved the way for various "relational" conceptions of the subject and autonomy (Mackenzie and Stoljar 2000). Second, this universality enables authors who mobilize this paradigm case to construe without much trouble the normative imperative of care. It is, after all, difficult to contend with the claim that infants require care in order to survive and thrive. The figure of the infant thus harbors great allegorical force. The innocence and helplessness of the dependent infant empowers authors to make an appeal for the inherent goodness of care. Finally, the infant's claim to the universality of dependency also tugs at the stigma commonly associated with being dependent on care, showing that dependency is not exceptional (let alone despicable), but ordinary.

At the same time, however, the great strengths of this paradigm case also point us toward some of its limitations. First, the normative link between dependency and care implicated by the figure of the infant might seduce writers into naturalizing the care relationship in terms of the practices it invites and the affects it engenders. Noddings's early work on care, which sometimes spoke of "natural caring" (Noddings 1984, 83), was often challenged in these terms (for example, Hoagland 1990). In that work, Noddings derived her ethic of care from a natural "impulse to care" for the dependent infant. By inviting such a naturalized conception of care, the paradigm case of the infant might coax its users into assuming that the caring impulse naturally follows from dependency itself-a claim that does not hold in the lives of many people who are dependent on care, as will become clear below. ${ }^{8}$ Many authors who draw on the paradigm case of the infant have grappled with this problem as they refined their accounts of dependency and care in response to such criticisms. Tronto had already warned about the risk of "romanticization" that might occur from attempting to generalize the mother-child relationship (Tronto 1993, 103); and Ruddick, whose work also relied heavily on observations derived from mothering, frequently sought to uncouple the ethic of care from essentialized notions about the mother-child relationship (Ruddick 1998, 13). ${ }^{9}$ Nonetheless, the risk of naturalizing care looms large when drawing on the paradigm case of the infant.

The importance of temporality in this paradigm case constitutes a second limitation. Although this case seems to assume that dependency is essentially a temporary condition (sometimes revisited in frail old age), not all instances of dependency are temporary. For example, for many physically or intellectually disabled persons, dependency will not gradually diminish. Such dependencies accentuate aspects of dependency that the paradigm case of the infant might not help us grasp very well, such as the asymmetry of dependency relations and the responsibility for caring. Parent-child relationships are generally accepted to be unequal, at least until adulthood, as the infant develops physically, mentally, and emotionally; this asymmetry may not surface as a moral problem as much as it does for persons whose dependency is permanent and extends beyond childhood, as in the case of physical disability. Moreover, since the paradigmatic parent-child relationship assumes caring responsibilities to lie firmly with the parent, it cannot shed light on cases of permanent dependency-dependency that extends beyond the parent's own death. These points also illustrate that those drawing on the paradigm case of the infant have in mind not just any infant, but one who is normatively construed as, for instance, being able-bodied and able-minded. This empirically narrow (as well as normative) conception of infancy results in philosophical limitations. The following paradigm cases all pick up some or all of these limitations of the paradigm case of the infant. 


\section{The Physically Disabled Person}

This paradigm case presents dependency as socially constructed-“a production of particular social relations" (Shakespeare 2000, 17). It assumes that a potentially autonomous person is consigned to dependency, often for nefarious reasons. If the paradigm case of the infant depicts dependency as an inevitable (if temporary) aspect of the human condition, the paradigm case of the physically disabled person proffers the thought that dependency is socially contingent and mutable, a result of unequal relations of power. Along with this conception of dependency also comes a more apprehensive approach to care, which is not seen as a natural response to dependency, but rather as its unwelcome cause. Some of the common associations with an infant's dependency-such as vulnerability and helplessness-remain, but the paradigm case of the physically dependent person no longer relates these as natural. The salient feature of dependency becomes its inevitable inequality.

The figure of the physically disabled person is found primarily in writings on dependency and care in the field of disability studies (for example, Barton 1989; Oliver 1989; Barnes 1991; Silvers 1995; Morris 1997; Shakespeare 2000; Silvers 2001). Authors use this paradigm case to scrutinize the common association of disability and dependency, which is perceived to be stigmatizing. Often drawing on the "social model" of disability (Oliver 1990; see also Shakespeare 2014), they focus on how institutions, conventions, and practices of care render people dependent. So, writes Mike Oliver, "the creation of dependency amongst disabled people is an inevitable consequence of the social policies that prevail in all modern industrial societies" (Oliver 1989, 9). Far from being a natural consequence of impairment, the figure of the physically disabled person provides a view of dependency as being caused by social relations. In this way, dependency becomes wellnigh synonymous with disability itself: a materialization of social inequality only contingently related to one's physical or mental situation (Shakespeare 2000, x).

Paradoxically, the paradigm case of the physically disabled person locates the root of the construction of dependency in the practice of care itself. It signifies someone who hypothetically could live her life in full autonomy but finds herself hampered by patronizing practices of care, which inhibit her capacities for self-determination and force her to relinquish control. Care becomes one component of the disabling social structures that the social model of disability seeks to expose. In this vein, Silvers contends that "the very structure of helping or caring relationships invites the marginalization of whoever is consigned to the position of dependence" (Silvers 1995, 40). A dependent person finds herself required to "profess incompetence" and to take up a subordinated stance in order to assure they will receive the care that is their rightful due (40). As a result, Silvers suggests, "submissiveness remains the price of good treatment" for dependent people (39). In this way, care creates dependency, which becomes the antithesis of personal autonomy. The paradigm case of the physically disabled person thus juxtaposes dependency with autonomy, self-determination, and control.

The paradigm case of the physically disabled person conceives of dependency as a potential source of exploitation or oppression. One of the insights this paradigm case offers, therefore, is that dependency can potentially be harmful by virtue of the inequality that logically seems to be characteristic of any relation of dependency-what Silvers calls its "fundamental asymmetry" (41). ${ }^{10}$ The figure of the physically disabled person thus provides analytical space for assessing the inequalities a relation of dependency might harbor, including the threats of violence, exploitation, and oppression. In addition, accounts of the asymmetry of relations of dependency also remind us of the 
importance of the value of autonomy-not only in principle but phenomenologically as well. The paradigm case of the physically disabled person shifts the gaze to what it feels like to be dependent and rendered powerless or out of control.

At the same time, however, this paradigm case's fixation on autonomy, selfdetermination, and control also comes at the cost of several limitations. First, construing dependency as a product of social relations risks reproducing a particular conception of the human subject that has been subject to a multitude of (often feminist) critiques (Winance 2016, 101). By juxtaposing dependency and autonomy, it cannot fathom the ways in which the problem of dependency calls into question familiar liberal notions of the autonomous self, nor of the ways in which dependency and autonomy might be intimately bound up (Kittay 1999; Fineman 2000; Mackenzie and Stoljar 2000; Anderson and Honneth 2004). Second, maintaining personal autonomy as an ideal that opposes dependency can serve to alienate and marginalize disabled persons for whom this ideal represents an unattainable standard. In this sense, this paradigm case (much like that of the infant) construes its empirical touchstone normativelythat is, able-minded and capable of organizing one's own life, at the very least. Third, and relatedly, this fixation on autonomy on the part of the dependent person risks effacing the role of the person engaging in practices of care, and the extent to which she might be subjected to forms of exploitation and oppression, both inside the dependency relationship and outside of it (Kittay 1999, 70).

Most important, however, might be that by condemning dependency as an unwelcome product of oppressive social relations, the paradigm case of the physically disabled person does little to mitigate the negative stereotypes associated with dependency. In fact, denouncing dependency as a source of powerlessness and the relinquishment of autonomy risks further stigmatizing the condition of dependency. In portraying dependency as a social construct that ought to be eradicated, the paradigm of the physically disabled person fosters the idea that dependency is antithetical to autonomy or even dignity. Silvers claims that "[a] dependent stance is advantageous only if genuine-that is, if the putative dependent is truly incompetent" (Silvers 1995, 40). Her statement leaves open the question whether all dependency is socially constructed (as she believes some are "truly" incompetent), but it nonetheless perpetuates its close association with incompetence. In this way, the paradigm case cannot resolve the stigma it seeks to redress.

Like that of the infant, the paradigm case of the physically disabled person must be understood in its historical condition of emergence. It arose at least in part in response to the claims about dependency made by authors drawing on the paradigm case of the infant. Its harsh critique of the myriad ways in which dependency might lead to asymmetry, inequality, and exploitation was in fact often aimed directly at care ethicists (for example, Silvers 1995; Morris 1997). Since then, many disability studies authors have taken up these limitations and sought to nuance their original accounts of dependency and have even embraced some aspects of care ethics-for instance, by recognizing that some forms of dependency are beyond the reach of social construction (for example, Watson et al. 2004; Shakespeare 2014). Nonetheless, this paradigm case continues to influence the "dependency debate" even in its original articulation (Keyes, Webber, and Beveridge 2015; Winance, Damamme, and Fillion 2015).

\section{The Profoundly Intellectually Disabled Person}

The paradigm case of the profoundly intellectually disabled person thinks about dependency in terms of a complete and unending need for care and assistance. ${ }^{11}$ It 
imagines the dependent person to be incapable of carrying out activities of daily living or even speaking. Since the dependent person cannot survive without care, theorists who draw on this paradigm case conceptualize care as a moral good and a social responsibility. Moreover, since the need for care is unending, care also arises as a particular social problem, since it may not be clear who will be willing and able to provide this care. This paradigm case has been developed most prominently by Kittay (Kittay $1999 ; 2001 ; 2009 ; 2011 ; 2015)$ and also appears in some form in the writing of authors such as Jenny Morris, Jon Vorhaus, and Stacy Simplican (Morris 2001; Vorhaus 2007; and Simplican 2015).

As I noted in the introduction, the phrase "paradigm case" originates in Kittay's work, where it denotes a hypothetical sort of "limit case" of a dependency relationship. However, this limit case is clearly informed by her own experiences, as Kittay's writing on dependency rarely goes without explicit reference to her daughter Sesha.

My daughter, a sparkling young woman, with a lovely disposition is very significantly incapacitated, incapable of uttering speech, of reading or writing, of walking without assistance, or, in fact, doing anything for herself without assistance. She has mild cerebral palsy, severe intellectual disability, and seizure disorders... . She is fully dependent and while at the age of 40 she (like us all) is still capable of growth and development, it is quite certain that her total dependence will not alter much... . It is only with care, and care of the highest quality, that she can be included, loved, and allowed to live a joyful and dignified life. (Kittay 2011, 51-52)

Kittay's description of Sesha summarizes the key points about dependency this paradigm case assumes: first, full dependence, and second, permanence. Much of Kittay's oeuvre is concerned with thinking through the moral and political consequences of the sort of dependency she witnesses in her daughter.

The paradigm case of the profoundly intellectually disabled person resembles some aspects of the infant. Both assume that dependency is (at least sometimes) inevitable; both assume that such dependencies are natural; and both draw positive moral directives from the need for care of people who are dependent. Both ground dependency in "the inevitable circumstances of the human animal" (Kittay 2001, 561; see also MacIntyre 1999). Their difference, however, lies in the permanence of the condition of dependency. Since the paradigm case of the infant (normatively envisioned as ablebodied and able-minded) suggests that dependency is a temporary state, care can be construed as circular and potentially reciprocal: it shapes children into caring individuals themselves, who might take up caring responsibilities for their parents or their own children. The paradigm case of the profoundly intellectually disabled person offers no such "solace" from dependency. Instead, care surfaces as a moral and social problem, as the willingness and ability to care constantly can no longer be taken for granted when reciprocity and circularity are taken out of the equation completely-and if dependency extends beyond the parent's death. If care no longer flows naturally from dependency, it becomes incumbent to organize it socially.

Focusing on dependency relations as one-sided and ongoing allows for several theoretical contributions. First, this paradigm case makes a strong case for revising the notion of the sort of autonomous, potentially self-sufficient subject that was at stake in the paradigm case of the physically disabled person. Instead, this paradigm case proffers the thought that self-determination is truly out of reach for some and 
that our philosophical models of subjecthood ought to recognize this fact (Kittay 2015, 57). In this way, the paradigm case of the intellectually disabled person can be regarded as a response to the paradigm case of the physically disabled person's fixation on autonomy and control, by magnifying some of the aspects that made the paradigm case of the infant so compelling. ${ }^{12}$

Second, underlining the permanence of this one-sided form of dependency also brings into view the plight of care workers who must devote a significant amount of time to ensure the well-being of the dependent person. "To advocate for my daughter without also advocating for those who are entrusted with her well-being is ance unjust and uncaring toward the caregiver" (Kittay 2001, 560-61). If care is nonreciprocal and unending, the social support for caregivers becomes a matter of moral urgency. In this way, the paradigm case of the profoundly intellectually disabled person invites us to think beyond the caregiver/receiver dyad to consider broader structures of caring support, or what Ruddick calls "triadic" relations "between worker, charge, and the 'providers' who secure and deliver. . . the resources on which dependency work depends" (Ruddick 2002, 217). For these writers, care becomes a social responsibility in addition to a moral demand on individuals.

Nonetheless, this paradigm case also brings a new set of limitations. First, as it assumes a fundamental one-sidedness to the dependency relation, the paradigm case of the profoundly intellectually disabled person risks losing a critical outlook on one potentially harmful consequence of this inequality: the danger of political marginalization. (This was one of the main lessons offered by the paradigm case of the physically disabled person.) Of course, this paradigm case like no other can sensitize theorists to the extreme vulnerability of dependents. Hence, Kittay observes that "the trust invested in the dependency worker not to abuse her power over the charge is enormous" (Kittay 2001, 561). Her answer lies in developing a caring attitude, the "virtue of care," which "secures the moral obligation to meet the needs of one who is vulnerable to your actions through an emotional bond" (561). Such a bond requires not only an effort on the part of the carer, but also a social organization of care that allows for such a bond to grow. However, authors like Laura Back believe that this account of dependency threatens to isolate dependent persons from society through the "prepolitical" relationship between caregiver and dependent. Back argues that "efforts to understand the interests of people who cannot adequately express themselves must draw on as many potential sources of insight as possible" and cannot rely solely on the primary caregiver (Back 2015, 122). By placing the caregiver as a spokesperson between the dependent person and the community, dependent persons are left with no access to the public sphere, which further adds to their political disenfranchisement. ${ }^{13}$

Second, and relatedly, postulating the absence of reciprocity also means that this paradigm case is liable to neglect how dependent persons can and do exert agency. It tends to leave little space for reciprocity, let alone for resistance, or what Winance calls "recalcitrance": "each person's capacity to say unexpected things, object, propose ways of living together, reach agreements, or even develop new qualities and thus become autonomous" (Winance 2016, 109; see also Erevelles 2011, 177; Simplican 2015, 224; Kane 2016, 166). ${ }^{14}$ Several authors who draw on the paradigm case of the intellectually disabled person have attempted to theorize agency-in-dependency: Vorhaus suggests that wholly dependent people can reciprocate by teaching their caregivers about dependency and the human condition (Vorhaus 2007), and Kittay surmises that the wholly dependent person restores reciprocity by making "a gift of her joy and her love" (Kittay 2011, 57). Nonetheless, these ideas seem to think about agency 
solely in terms of possible gifts the carer might choose to receive in her work. As such, these responses do not fully address the core criticism, which is that the power dynamic in relationships of dependency might be more complex than this paradigm case can acknowledge-the sort of "complex dependency" Simplican theorizes, in which "dependents find ways to exercise power amid vulnerability" (Simplican 2015, 224). Drawing on the paradigm case of the profoundly intellectually disabled person brings the risk of losing sight of the agency of the dependent.

\section{The Refugee}

The paradigm case of the refugee denotes someone whose ability to ascertain survival and flourishing (the need for care) hinges on structural and contingent historical conditions. This paradigm case thus foregrounds the social and political nature of dependency-dependency "on those we do not know" (Butler 2004b, 23). More so than any of the other three paradigm cases, it locates dependency in the large web of social relations that make up the social, rather than in singular care relationships. It zooms out from the "archetypical" dependency dyad of caregiver and care recipient to offer a sort of bird's-eye view of dependency as fundamental to the social fabric. Because of this, a primary dependency on others is ontologically inevitable, but this dependency is exacerbated in particular political circumstances. As a result, care becomes highly morally ambiguous, both a necessity for survival and a source of violence.

I trace this paradigm case back to the work of Butler primarily (Butler 2004a; 2004b; 2010; 2017; forthcoming). Butler has engaged relatively little with the other three paradigm cases, and her work is rarely in direct conversation with them. This separates the refugee from the other paradigm cases, which in part developed in conversation with one another. Nonetheless, I believe her take on dependency fits well into this discussion, as she grapples with many of the issues first encountered in the paradigm case of the infant. The paradigm case of the refugee can also be found in the work of authors who have drawn on Butler to further reflect on dependency and care (for example, Simplican 2015; 2017).

Distinctive for the paradigm case of the refugee is that it shifts attention to the anonymity of dependency relations. Butler speaks of humans as "laid bare from the start, dependent on those we do not know... . We come into the world unknowing and dependent, and, to a certain degree, we remain that way" (Butler 2004b, 23). To be sure, Butler roots this condition of dependency in an ontological state of vulnerability, writing that humans are "beings who are, by definition, physically dependent on one another, physically vulnerable to one another" (Butler 2004a, 27). In this sense, her rendition of dependency calls to mind the paradigm case of the infant to a certain degree. However, where the paradigm case of the refugee differs from that of the infant is in how it deduces from this state of vulnerability a dependency on those we do not know. The locus of dependency thus ceases to be only the caregiving dyad: instead, the refugee denotes "dependency on people we know, or barely know, or not know at all" (Butler 2010, 14). Herein lies the anonymity of dependency: our most notable dependencies, the ones that determine to a large extent our ability to sustain our lives, are not necessarily a product of our relationship to those with whom we find ourselves entangled in direct relationships of care, but a product of our ties to larger social bodies, structures, and systems. ${ }^{15}$

Moreover, the anonymous sort of dependency highlighted by the figure of the refugee also renders dependency inherently politically inflected, as the plight of the refugee is marked primarily by an anonymous dependency on "social and economic forms of 
life" that allocate "the social conditions of organic persistence" (Butler 2017). She explains: "whether a body that falters and falls is caught by networks of support or whether a moving body has its way paved without obstruction depends on whether a world has been built for both its gravity and mobility-and whether that world can stay built" (Butler forthcoming). In Butler's account, the refugee cannot rely on intimate care relations for the provision of shelter, clothing, and health; rather, the availability of such necessities for survival is dependent on a social organization geared toward at least potentiating survival. This is why Butler calls dependency "unbearable": it is a necessary, but threatening condition, which leaves humans vulnerable not only to one another, but particularly to the social structures that organize human life (Butler 2017).

From this rendition of dependency follows an ambivalent ethical sensibility toward caring, for two reasons. First, in the face of anonymous dependency, the assurance of care becomes highly uncertain; by undoing the primacy of the caregiving dyad, this paradigm case also dislodges caring responsibilities from a specific caregiving agent. Second, care itself "can emerge precisely as the instrument of aggression and destruction," as it harbors the risks of paternalism, exploitation, and oppression, not only within the caregiving dyad, but particularly on a structural level. Consequently, Butler seems convinced that care dependency cannot indicate a pathway either toward an ethic of caring or toward a politics of care (Butler 2017).

The paradigm case of the refugee accentuates different aspects of dependency than do the other paradigm cases. First, highlighting "anonymous" dependency fully shifts attention from what Lorraine McCrary calls "engaged care" of private relations to what she calls "extended care": "care that is less personal, particular, and relational, such as the care one might exhibit toward other members of a large association or toward other citizens of a country" (McCrary 2019, 64-65). Consequently, its take on dependency has dependency on care overlap with political and economic dependency, as the allocation and (mis)use of care are determined by structural conditions. ${ }^{16}$ Second, approaching dependency as a historically and politically contingent condition brings into view the social distribution of dependency, which may be exacerbated for some and diminished for others. In this way, dependency is not necessarily an equalizing aspect of the human condition but can also serve to deepen inequalities. Third and finally, in providing an account of dependency that is both ontologically inevitable and socially contingent, the paradigm case of the refugee opens up ample space for agency, resistance, and even aggression amid (or because of) dependency - without having to denounce dependency altogether. Silvers's association between dependency and subservience forced her to reject the former, but Butler locates in dependency also the source of politically potent outrage, exemplified by the persistence and even resistance of refugees in the European "refugee crisis." This paradigm case thus manages to incorporate agency as part of the condition of (inevitable) dependency. (Here, it speaks to the problem with agency noted in the paradigm case of the intellectually disabled person.)

Nonetheless, the paradigm case of the refugee, too, can only be invoked at some analytical cost. The most significant cost is that this paradigm case feeds a suspicion toward care that does not always seem fully justified, nor beneficial to people who find themselves dependent on care. Although the paradigm case helpfully brings to attention the convergence of care and violence, opening up fecund philosophical ground (for example, Simplican 2017), it is not apparent how this observation should affect those whose dependency on care is total and permanent, such as persons who are profoundly intellectually and/or physically disabled (let alone infants). Indeed, those who draw on the paradigm case of the refugee are reluctant to construe clear normative directives based 
on the value of care. ${ }^{17}$ As such, the paradigm case does not provide insights that could help us to distinguish between "good" and "bad" forms of care, nor proposals for turning violent care into care that nurtures and enables humans to flourish. This "resistance to normative ethical inquiry" makes it difficult to ascertain how dependency ought to be valued and treated (Mackenzie, Rogers, and Dodds 2014, 3). This ambivalence will scarcely serve the interests of those who are dependent on the sort of interpersonal, intimate care from which the paradigm case of the refugee ushers us away.

\section{The Logic of the Paradigm Cases (and their Limitations)}

At the start of this article, I suggested that many authors who appear to share a vocabulary of dependency are in fact not writing about quite the same phenomenon-hence the many ontological and ethical disagreements in the "dependency debate." This is because authors draw their theories from different empirical touchstones. To show this, I have traced and isolated four paradigm cases of dependency in care relations. Each of these (sometimes highly normatively construed) paradigm cases takes the most salient features of a particular empirical example and abstracts these into a theoretical concept of dependency. This concept of dependency, in turn, philosophically permits (or even necessitates) a particular ethical stance. This is why I proposed in the introduction using Kittay's phrase "paradigm case": much like her ostensibly hypothetical paradigm case, each of these abstract philosophical renditions of dependency is at least tacitly informed by a specific empirical example, which accentuates particular characteristics of the dependency relationship. As authors extrapolate from their paradigm cases to general accounts of dependency, their takes on dependency end up being in conflict. In this way, the different paradigm cases appear to be at the root of the "dependency debate." In what remains, I will offer some further reflections on the philosophical implications of the use of paradigm cases of dependency.

Up to this point, I have presented the paradigm cases as synthesized constructs, each taking cues from a variety of authors. I have already emphasized that it is not my aim to assess and interrogate particular authors who use a particular paradigm case, but I do wish to stress that their argumentative logic is nonetheless clearly observable in the work of individual authors. A heuristic benefit of isolating paradigm cases as I have done is that they can help tease out this logic in particular theories of dependency.

To illustrate this point, consider a theoretical U-turn such as the one Morris seems to have made in her writing on dependency and care (Morris 1997; 2001). In her earlier writing on care, Morris had offered a particularly forceful renunciation of dependency, claiming that "[p]eople who are said to need caring for are assumed to be unable to exert choice and control. One cannot, therefore, have care and empowerment, for it is the ideology and the practice of caring which has led to the perception of disabled people as powerless" (Morris 1997, 54, emphasis in original). Morris's juxtaposition of dependency and autonomy leads her to unequivocally reject the former. (The title of the article, "Care or Empowerment?," is telling enough.) Clearly, Morris's point relies on the paradigm case of the physically disabled person in order to work at all.

In the course of four years, however, Morris's outlook on care and dependency had changed dramatically. In a new essay, she explored ethics of care literature to supplement her original view of dependency as a disabling social construct to reflect on the need for assistance sometimes brought about by bodily impairment: "[w]e need to challenge the social construction of dependency, but we should not at the same time deny the experience of our bodies and the consequences for the provision of assistance" 
(Morris 2001, 14). As an explanation for her newly formed position, Morris offered the following anecdote:

Communication and cognitive impairments-like physical impairments - also create a particular type of dependency on others. This fact was starkly brought home to me in my recent research concerning young disabled people who have high levels of support needs. I visited one young man at the residential school he had been attending since the age of four. According to his parents, care staff, and teachers he had no way of indicating "yes" or "no," no way of communicating his preferences or choices. When I observed him in classrooms and where he lived, he had no discernible interaction with others.... During the course of the research project he left school and went back to live with his parents. I visited him at the day center he now attends. There I observed him actively participating in relationships with the care staff and other disabled young people... . This transformation had been brought about by a "care" relationship which started with his human right to communicate and which sought ways to make this possible. His impairment meant that this young man depended entirely on others to recognize and facilitate his access to this most fundamental of human rights. (14)

Morris's encounter with someone who was profoundly intellectually disabled thus shone new light on her original conception of dependency. She had literally found an alternative empirical touchstone-and it demanded a radical revision of her previous position. The example of Morris shows the extent to which the paradigm cases can inform an author's argument-not only in their rendition of dependency, but in their normative outlook on care, too.

Morris's example renders the philosophical logic of the paradigm case quite apparent: a particular empirical example informs a particular conception of dependency, which, in turn, directs the author toward a particular ethical sensibility toward care. This makes the paradigm cases analytically potent. Nonetheless, the paradigm case has its philosophical drawbacks, too. As we have seen, each paradigm case comes with limitations-aspects of dependency a particular paradigm case might risk downplaying or fail to illuminate, because its salient features point elsewhere. (This, as Nauta observed, is inherent to the use of "exemplary situations" [Nauta 1984, 366]) One cause of these limitations is that the paradigm cases are a product of abstraction. The move of theoretical abstraction necessarily means leaving out some of the less noticeable aspects of each paradigm case. In this sense, no single paradigm case as such is real. In order to function properly, each has to compromise on getting at the moral complexity of actual, lived-through relations of dependency. However, the move of abstraction can only partially explain how these limitations come about. Recall Morris's argumentative leap. She amended her position on care after she had met a person with profound intellectual disabilities; but was it impossible to find a redeeming quality of care within her original paradigm case? Probably not, as evidenced by later reflections on physical disability from authors like Winance and Tom Shakespeare (Winance 2010; Shakespeare 2014). For them as well as others, dependency ceased to be a social construct analogous with physical disability itself. This suggests that although each paradigm case places different accents, each could also be utilized to explore a wider range of dependencies, some even associated with other paradigm cases-if carefully considered. The curious fact remains, however, that many authors seem not to have done so. Which raises the question: why? 
I believe the answer lies in the link between the paradigm cases and their associated normative stance toward care. As we have seen, aside from providing the empirical reference point for a particular philosophical account of dependency itself, each paradigm case also enables and supports a particular normative orientation toward caring. The rendition of dependency influences the ethical appraisal of caring. It thus appears that how we understand dependency determines how we value care-and the paradigm cases play a crucial role in establishing this link.

I contend that if we accept the claim that a particular rendition of dependency enables or even calls for a particular ethical sensibility toward care, we may also accept the reverse: that upholding a particular ethical sensibility toward care requires a particular rendition of dependency to become plausible. By sensitizing us to particular characteristics of dependency (which, in the empirical example in question, are made to appear salient) the paradigm cases work to bolster particular normative claims about care. In this way, the paradigm cases can also be used strategically to sustain ethical arguments about caregiving - at the cost of a narrow (and sometimes highly normative) depiction of the empirical example in question.

The rhetorical prowess of the paradigm cases is of importance here. By drawing on a rich repository of cultural assumptions and imaginings about the empirical examples they contain, each paradigm case capitalizes on some aspects or associations of dependency while minimizing others. In this way, paradigm cases come to bear the force of common sense, bringing a sense of moral urgency to arguments about care. A particular normative (as well as political) position seems to follow from the paradigm cases almost by default. In this way, the use of paradigm cases might also be strategic: through empirical example, they provide a highly specific (and selective) rendition of dependency, which validates a particular ethical claim about care. ${ }^{18}$ The argument, then, is not just that the empirical examples informing these paradigm cases have some inherent characteristics that limit the range of dependencies they can realistically illuminate; rather, it seems to me that strategic considerations also have sometimes kept authors from exploring the full implications of their empirical example.

This supposition goes a long way toward explaining the controversies surrounding the concept of "dependency" this article seeks to address. The paradigm cases of dependency do not simply indicate a particular ethical sensibility toward care, as if it would follow naturally from empirical example; they are also brought up to facilitate arguments about care. If a particular rendition of dependency implores a specific ethical appraisal of care, the reverse is also true: a particular normative stance toward care might determine which aspects of dependency will appear as salient. However, this also alludes to the philosophical limit of the paradigm cases. Because if it is true that the paradigm cases serve to augment particular ethical appraisals of care, it could well follow that our normative orientation toward care will influence what sorts of dependency we see-and, by extension, which aspects of dependency we fail to notice.

Nevertheless, I do consider the paradigm cases as I have reconstructed them here to be philosophically fruitful. As we have seen, dependency can be inevitable or imposed; temporary or permanent; universal or contingent; and dyadic or anonymous. Although strategic use of the paradigm cases might lead to overly narrow depictions of dependency, no single paradigm case seems to manage to grasp all these aspects of dependency all at once. In their juxtaposition, however, a more complex take of dependency begins to emerge, and the normative link between dependency and care begins to lose its consistency. Each paradigm case helps illuminate aspects of dependency previously out of view. There is philosophical potential, then, in bringing the paradigm cases into 
dialogue. By taking up the theoretical challenge of a contrasting paradigm case, authors can hone their theories of dependency and broaden the reach of their argument. Morris, whom I discussed above, is one author who has sought to mine this potential. I will provide two additional examples below.

First, consider Kittay's argument for "managing" dependency in the lives of disabled people-to "acknowledge its presence in our lives" yet "protect against the fault lines that are part and parcel of our condition as dependent beings" (Kittay 2015, 58). She writes:

A consideration of dependency forces the question: can one still protect the benefits to be gained by disabled people's demands for independence without re-stigmatizing those who do not benefit? Can we accept the inevitability of dependence without denying the negative effects of an imposed dependency on the lives of many disabled people? (57)

By distinguishing between "the inevitability of dependence" and "imposed dependency," Kittay explores how the insights offered by the paradigm cases of the physically disabled person and the profoundly intellectually disabled person can inform a more complex understanding of the moral demands that dependency might make. Her argument for "managing" dependency centers on the thought that though dependency can be inevitable, it is not always so, and mitigating the negative experiences that dependency might engender requires a meticulous organization of care and assistance.

Second, consider Simplican's account of “complex dependency." Her concept seeks to describe a form of dependency "in which individuals inhabit both intense vulnerability and aggressive power" (Simplican 2015, 219), a condition she attributes specifically to persons with autism whose aggressive behavior can lead to violent abuse. As Simplican recognizes that some forms of dependency are inevitable and everlasting (for example, due to bodily impairments), her account relies on the paradigm case of the profoundly intellectually disabled person. However, by coupling dependency to agency (in the form of aggression and violence that overturns the care relationship) "complex dependency" also brings to mind the paradigm case of the refugee. Moreover, Simplican's attention to the responsibility of communities to care for people whose dependency is complex recalls the anonymous dependency central to the latter paradigm case. By combining paradigm cases, Simplican helps us consider dependencies both inevitable and contingent, as well as dependents both helpless and powerful.

\section{The Seductions of Abstraction}

I have sought in this article to show how theoretical disputes about dependency often boil down to disagreements about the sort of condition dependency is marshalled to signify. Writers draw on different empirical touchstones, which lead them to conceptualize dependency differently, resulting in a different ethical sensibility toward care as well. Taking a phrase from Kittay, I have called these empirical touchstones paradigm cases of dependency. One upshot of isolating the paradigm cases has been the insight that how we understand and value dependency seems to determine how we understand and value care, and vice versa. From this, I have argued that our normative orientation toward care might influence what sorts of dependency we see-and, by extension, which forms of dependency we fail to notice. Bringing contrasting paradigm cases into dialogue, as in the work of Morris, Kittay, Simplican, and others, is one way of reckoning with this problem. 
At this point, I should probe the question of whether the singular word dependency can carry the conceptual weight thrown at it by so many different authors. One could argue that a terminological diversification within the theory of dependency is in order. Rather than arguing about the ontological and moral ramifications of a singular concept-dependency-a more fruitful direction could be to semantically differentiate between the various forms of dependency each paradigm case outlines: inevitable or imposed; temporary or permanent; universal or contingent; and dyadic or anonymous. Several authors have already attempted to provide an augmented lexicon, for instance by exploring the relationship between dependency and vulnerability (for example, Dodds 2014; Scully 2014; Engster 2019). The introduction of precariousness and precarity constitutes another potential avenue for conceptual diversification (for example, Butler 2004a; Butler 2010; Murphy 2011; Lorey 2015). I welcome these interventions, but I also believe there is an argument for sticking with a word that so many authors feel compelled to use, even if they make such different points. Evidently, dependency matters to theorists of care, which is a fact that merits attention. In fact, as the paradigm cases demonstrate, our ethical appraisal of care often relies on it. If this is true, it is a contested concept by necessity, and its descriptive content is inevitably normatively charged. ${ }^{19}$

I wish to make a final remark on the use of paradigm cases in the drawing up of philosophical arguments about dependency. In his discussion of "exemplary situations," Nauta contends that it is not up to philosophers to defend a particular exemplary situation. Rather, he writes, "[p]hilosophers explore the limits of the exemplary situations concerned" (Nauta 1984, 376). Moreover, they can ask whether a new exemplary situation is in order, one that more adequately fits the phenomenon to be analyzed. It is not about getting it right. It is about finding "new interpretations" of the reality in which we live-ones that resonate with the present (366). In this regard, it seems to me that these four paradigm cases of dependency have lost none of their viability. To be sure, their renditions of dependency are incomplete and sometimes based on normative assumptions. But they are incomplete not by fault, but by design.

Nonetheless, it has become clear that a normative stance on care might get in the way of sufficiently addressing (or even noticing) particular aspects of dependency. How might we theorize dependency more holistically? I have already suggested a first way. Juxtaposing paradigm cases can lead to new theoretical insights. Another method might be found in diving into the messy reality of actual relations of dependency-for instance by combining philosophical inquiry and qualitative work, as in methods pursuing an "empirically grounded ethics of care" (for example, Leget, Borry, and de Vries 2009; Pols 2015; Vosman, Timmerman, and Baart 2018; Van der Weele, Bredewold, Leget, and Tonkens 2020). This is not to say that any argument about dependency must account for the fleshly stuff of qualitative inquiry. Rather, I am advocating for an awareness of the seductions of abstraction, and the limits of one's account, owing to the variability of actual, lived-through dependency.

Acknowledgments. I am indebted to Evelien Tonkens, Carlo Leget, Femmianne Bredewold, Allegra Reinalda, Stacy Clifford Simplican, Christine Bigby, Gbemende Johnson, Inge van Nistelrooij, Hanne Laceulle, and the anonymous Hypatia referees for their insightful and challenging comments on earlier drafts of this article.

\section{Notes}

1 Anyone writing on disability is faced with a dilemma of terminology: that of choosing to write either "disabled person" (“identity-first" language) or "person with disability" ("person-first" language). 
Preferences vary among scholars of disability. In this article, I use both interchangeably. For the (rather pragmatic) sake of brevity, however, I mostly opt for "disabled person."

2 Shildrick 2000; Butler 2004a; and Lorey 2015 are prominent examples, as well as the essays in Mackenzie, Rogers, and Dodds 2014. The precise relationship between dependency and vulnerability has been conceived of in various ways, but a thorough examination of this link lies beyond the scope of this article. For worthwhile attempts, see, for example, Fineman 2008; Dodds 2014; and Scully 2014.

3 More than one author has singled out "interdependence" as the answer to ongoing disagreements about dependency. See, for instance, Reindal 1999; Watson et al. 2004; Fine and Glendinning 2005; and Back 2015. A comprehensive discussion of the concept of interdependency is not my aim here. I join Kittay in believing that "interdependence begins with dependence" (Kittay 1999, xii); by studying paradigm cases, I am interested in dependency as a concrete, possibly one-sided relationship of caring.

4 Kittay herself has considered in some detail the relationship between her philosophical argument and its empirical roots. See, for instance, Kittay 2002; 2019.

5 I use care theory in the broadest possible sense of the term: as a field to which any author belongs who has theorized about care, be it from the angle of care ethics, liberal philosophy, disability studies, or another field entirely.

6 The elderly person features in many writings on dependency, usually in the same breath with the infant, when both infancy and frail old age are considered part of a universal human condition (for example, Kittay 1999). I will not go into the differences between the two examples here, but see Baltes 1996 and The 2008 for some indications. The network, often featured in writings from the perspective of science and technology studies, would locate the need for care (that is, dependency) not in specific subjects, but rather in the interaction between actors and their environments. See, for instance, Moser 1999; López Gómez 2015; and Winance 2016.

7 This depiction of dependency in infancy relies on the notion that the infant will at some point acquire the necessary competencies to care for others. For consideration of the normativity of this view, see Kittay 1999, 163-73.

8 In addition, theories of care that characterize care as a "natural impulse" risk what Diemut Grace Bubeck calls "mystifying" care (Bubeck 2002, 166).

9 Nonetheless, Ruddick's attempts often garnered critiques (notably from María Lugones) for being tacitly essentialist and ethnocentric. For a thorough discussion of these critiques, see Keller 2010.

10 This "fundamental" asymmetry has also been admitted and analyzed by proponents of other paradigm cases of dependency, such as Tronto and Noddings (Noddings 1984, 66; Tronto 1993, 145-46). My point is that the paradigm case of the physically disabled person marks this asymmetry as a matter of urgency, as a moral problem requiring a prompt solution, because it frames this asymmetry as contingent, rather than given. 11 The most accurate term would be "profound intellectual and/or multiple disabilities." Most intellectually disabled persons do not resemble the group of persons with profound intellectual and/or multiple disabilities I have in mind here. In fact, the ambiguity about the care needs of people with mild or moderate intellectual disabilities is often one of the major stakes in debates on dependency (Cushing and Lewis 2002; Van Hove et al. 2012).

12 See Kittay 2011 for an example of how the paradigm case of the profoundly intellectually disabled person has been leveraged to critique disability studies accounts of dependency and care.

13 Kittay's insistence on a "virtue of care" has also garnered critiques in a different vein. Simplican, for instance, is not convinced by Kittay's reliance on this emotional bond: she contends that Kittay's account is prone to the charge of romanticizing care, as she trusts in "loving experiences of care, thus obscuring the everyday struggles of carers and dependents" (Simplican 2015, 220). This resembles the charge of "romanticizing care" leveled against the paradigm case of the infant. Apparently, the paradigm case of the intellectually disabled person cannot entirely escape this charge either, in spite of its increased attention on the political nature of caring obligations.

14 In Learning from My Daughter, Kittay uses the phrase "genuine needs and legitimate wants" to express a similar concern for the agency of the dependent person (Kittay 2019, 174).

15 Butler terms this fundamentally social nature of dependency "precariousness." Precariousness denotes the existential condition "that life requires various social and economic conditions to be met in order to be sustained as a life" (Butler 2010, 13-14). The condition of precariousness comprises a number of dependencies of varying scale, all rooted in the vulnerability of the physical body in its exposure to others. For a more thorough discussion of precariousness, see also Murphy 2011; Lorey 2015. 
16 It is helpful here to recall the four registers of dependency distinguished by Nancy Fraser and Linda Gordon and the fifth added by Kittay: 1) economic, 2) sociolegal, 3) political, 4) moral/psychological, and 5) biological (Fraser and Gordon 1994; Kittay 2015). Multiple paradigm cases combine several of these registers, but only the refugee insists that they cannot be understood separately-that biological dependency is also fundamentally political and economic, for instance.

17 In the context of the ethical implications of her argument, Butler does speak of "our reciprocal obligations to produce together conditions of livable life" (Butler 2017), by which she seems to mean at least an obligation for social democracy and institutions that nurture the sustenance of human and nonhuman life. Yet though such a democracy is to be geared toward "flourishing," it does not become entirely clear from Butler's account what would constitute such "flourishing." The value that lies in sustaining life and enabling it to thrive is not explicated.

18 In this respect, I believe my use of the phrase "paradigm case" diverges from Nauta's "exemplary situation." For Nauta, the specificities of the exemplary situation seem to wholly determine the course a philosopher's argument can take (Nauta 1984, 375). This is not so for these paradigm cases of dependency: in their attempt to support a particular normative claim about care, authors might choose to leave some of the less prominent characteristics of a particular empirical example of dependency undertheorized.

19 For "essentially contested concepts," see Gallie 1956.

\section{References}

Adams, Rachel. 2017. Choosing disability, visualizing care. Kennedy Institute of Ethics Journal 27 (2): 301-21.

Anderson, Joel, and Axel Honneth. 2004. Autonomy, vulnerability, recognition, and justice. In Autonomy and the challenges to liberalism: New essays, ed. John Christman and Joel Anderson. Cambridge, UK: Cambridge University Press.

Back, Laura. 2015. Private dependence, public personhood: Rethinking “nested obligations." Hypatia 30 (1): $115-31$.

Baltes, Margret M. 1996. The many faces of dependency in old age. Cambridge, UK: Cambridge University Press.

Barnes, Colin. 1991. "Cabbage syndrome": The social construction of dependence. London: The Falmer Press. Barton, Len. 1989. Editor's introduction. In Disability and dependency, ed. Len Barton. London: The Falmer Press.

Bubeck, Diemut Grace. 2002. Justice and the labor of care. In The subject of care: Feminist perspectives on dependency, ed. Eva Feder Kittay and Ellen K. Feder. London: Rowman and Littlefield.

Butler, Judith. 2004a. Precarious life: The powers of mourning and violence. London: Verso.

Butler, Judith. 2004b. Undoing gender. New York: Routledge.

Butler, Judith. 2010. Frames of war: When is life grievable? London and New York: Verso.

Butler, Judith. 2017. Bodies that still matter. Lecture delivered at Resonances of Judith Butler Conference. April 5-6. Amsterdam.

Butler, Judith. forthcoming. Bodies that still matter. In Bodies that still matter: Resonances of the work of Judith Butler, ed. Annemie Halsema, Katja Kwastek, and Roel van den Oever. Amsterdam: Amsterdam University Press.

Collins, Stephanie. 2015. The core of care ethics. London: Palgrave Macmillan.

Cushing, Pamela, and Tanya Lewis. 2002. Negotiating mutuality and agency in care-giving relationships with women with intellectual disabilities. Hypatia 17 (3): 173-93.

de Beaufort, Inez. 2013. Kleine ode aan de onafhankelijkheid. The Hague: Centrum voor Ethiek en Gezondheid.

Dodds, Susan. 2014. Dependence, care, and vulnerability. In Vulnerability: New essays in ethics and feminist philosophy, ed. Catriona Mackenzie, Wendy Rogers, and Susan Dodds. Oxford: Oxford University Press.

Engster, Daniel. 2019. Care ethics, dependency, and vulnerability. Ethics and Social Welfare 13 (2): 100-14.

Erevelles, Nirmala. 2011. Disability and difference in global contexts: Enabling a transformative body politic. New York: Palgrave Macmillan.

Fine, Michael, and Caroline Glendinning. 2005. Dependence, independence or inter-dependence? Revisiting the concepts of "care" and "dependency." Ageing and Society 25: 601-21. 
Fineman, Martha Albertson. 2000. Cracking the foundational myths: Independence, autonomy, and selfsufficiency. Journal of Gender, Social Policy and the Law 8 (13): 13-29.

Fineman, Martha Albertson. 2008. The vulnerable subject: Anchoring equality in the human condition. Yale Journal of Law and Feminism 20 (1): 1-23.

Fraser, Nancy, and Linda Gordon. 1994. A genealogy of dependency: Tracing a keyword of the U.S. welfare state. Signs 19 (2): 309-36.

Gallie, W. B. 1956. Essentially contested concepts. Proceedings of the Aristotelian Society, New Series 56: $167-98$

Held, Virginia. 1993. Feminist morality: Transforming culture, society, and politics. Chicago and London: University of Chicago Press.

Held, Virginia. 2006. The ethics of care: Personal, political, and global. Oxford: Oxford University Press.

Hoagland, Sarah Lucia. 1990. Some concerns about Nel Noddings' "Caring." Hypatia 5 (1): 109-14.

Hughes, Bill, Linda McKie, Debra Hopkins, and Nick Watson. 2005. Love's labours lost? Feminism, the disabled people's movement and an ethic of care. Sociology 39 (2): 259-75.

Kane, Laura Wildemann. 2016. Childhood, growth, and dependency in liberal political philosophy. Hypatia 31 (1): 156-70.

Keller, Jean. 2010. Rethinking Ruddick and the ethnocentrism critique of Maternal Thinking. Hypatia 25 (4): 834-51.

Kelly, Christine. 2013. Building bridges with accessible care: Disability studies, feminist care scholarship, and beyond. Hypatia 28 (4): 784-800.

Keyes, Sarah E., Sarah H. Webber, and Kevin Beveridge. 2015. Empowerment through care: Using dialogue between the social model of disability and an ethic of care to redraw boundaries of independence and partnership between disabled people and services. ALTER: European Journal of Disability Research 9 (3): 236-48.

Kittay, Eva Feder. 1999. Love's labor: Essays on women, equality, and dependency. New York: Routledge.

Kittay, Eva Feder. 2001. When caring is justice and justice is caring: Justice and mental retardation. Public Culture 13 (3): 557-79.

Kittay, Eva Feder. 2002. Love's labor revisited. Hypatia 17 (3): 237-50.

Kittay, Eva Feder. 2009. The personal is philosophical is political: A philosopher and mother of a cognitively disabled person sends notes from the battlefield. Metaphilosophy 40 (3-4): 606-27.

Kittay, Eva Feder. 2011. The ethics of care, dependence, and disability. Ratio Juris 24 (1): 49-58.

Kittay, Eva Feder. 2015. Dependency. In Keywords for disability studies, ed. David Serlin, Benjamin Reiss, and Rachel Adams. New York: New York University Press.

Kittay, Eva Feder. 2019. Learning from my daughter: The value and care of disabled minds. New York: Oxford University Press.

Kröger, Teppo. 2009. Care research and disability studies: Nothing in common? Critical Social Policy 29 (3): 398-420.

Leget, Carlo, Pascal Borry, and Raymond de Vries. 2009. "Nobody tosses a dwarf!" The relation between the empirical and the normative reexamined. Bioethics 23 (4): 226-35.

López Gómez, Daniel. 2015. Little arrangements that matter. Rethinking autonomy-enabling innovations for later life. Technological Forecasting and Social Change 93 (April): 91-101.

Lorey, Isabell. 2015. State of insecurity: Government of the precarious. London: Verso.

MacIntyre, Alasdair. 1999. Dependent rational animals: Why human beings need the virtues. Chicago: Open Court.

Mackenzie, Catriona, and Natalie Stoljar. 2000. Introduction: Autonomy refigured. In Relational autonomy: Feminist perspectives on autonomy, agency, and the social self, ed. Catriona Mackenzie and Natalie Stoljar. New York and Oxford: Oxford University Press.

Mackenzie, Catriona, Wendy Rogers, and Susan Dodds. 2014. Introduction: What is vulnerability, and why does it matter for moral theory? In Vulnerability: New essays in ethics and feminist philosophy, ed. Catriona Mackenzie, Wendy Rogers, and Susan Dodds. Oxford: Oxford University Press.

Manschot, Henk. 1994. Kwetsbare autonomie: Over afhankelijkheid en onafhankelijkheid in de ethiek van de zorg. In Ethiek van de zorg: Een discussie, ed. Henk Manschot and Marian Verkerk. Amsterdam: Boom.

McCrary, Lorraine Krall. 2019. From Hull-House to Herland: Engaged and extended care in Jane Addams and Charlotte Perkins Gilman. Politics and Gender 15 (1): 62-82. 
Mol, Annemarie. 2008. I eat an apple: On theorizing subjectivities. Subjectivity 22: 28-37.

Morris, Jenny. 1997. Care or empowerment? A disability rights perspective. Social Policy and Administration 31 (1): 54-60.

Morris, Jenny. 2001. Impairment and disability: Constructing an ethics of care that promotes human rights. Hypatia 16 (4): 1-16.

Moser, Ingunn. 1999. Good passages, bad passages. In Actor network theory and after, ed. John Law and John Hassard. Oxford: Blackwell.

Murphy, Ann. 2011. Corporeal vulnerability and the new humanism. Hypatia 26 (3): 575-90.

Nauta, Lolle. 1984. Historical roots of the concept of autonomy in Western philosophy. Praxis International 4 (4): 363-77.

Noddings, Nel. 1984. Caring: A feminine approach to ethics and moral education. Berkeley: University of California Press.

Nussbaum, Martha. 2006. Frontiers of justice: Disability, nationality, species membership. Cambridge, Mass.: Harvard University Press.

Oliver, Mike. 1989. Disability and dependency: A creation of industrial society? In Disability and dependency, ed. Len Barton. London: The Falmer Press.

Oliver, Mike. 1990. The politics of disablement. London: Macmillan Education.

Oliver, Kelly. 2002. Subjectivity as responsivity: The ethical implications of dependency. In The subject of care: Feminist perspectives on dependency, ed. Eva Feder Kittay and Ellen K. Feder. London: Rowman and Littlefield.

Pols, Jeannette. 2015. Towards an empirical ethics in care: Relations with technologies in health care. Medicine, Health Care and Philosophy 18 (1): 81-90.

Reindal, Solveig. 1999. Independence, dependence, interdependence: Some reflections on the subject and personal autonomy. Disability and Society 14 (3): 353-67.

Ruddick, Sara. 1995. Maternal thinking: Toward a politics of peace. Boston: Beacon Press.

Ruddick, Sara. 1998. Care as labor and relationship. In Norms and values: Essays on the work of Virginia Held, ed. Joram G. Haber and Mark S. Halfon. Lanham, Md.: Rowman and Littlefield.

Ruddick, Sara 2002. An appreciation of Love's Labor. Hypatia 17 (3): 214-24.

Schram, Sanford. 2000. After welfare: The culture of postindustrial social policy. New York: New York University Press.

Scully, Jackie Leach. 2014. Disability and vulnerability: On bodies, dependence, and power. In Vulnerability: New essays in ethics and feminist philosophy, ed. Catriona Mackenzie, Wendy Rogers, and Susan Dodds. Oxford: Oxford University Press.

Shakespeare, Tom. 2000. Help. Birmingham, UK: Venture Press.

Shakespeare, Tom. 2014. Disability rights and wrongs revisited. London and New York: Routledge.

Shildrick, Margrit. 2000. Becoming vulnerable: Contagious encounters and the ethics of risk. Journal of Medical Humanities 21 (4): 215-27.

Silvers, Anita. 1995. Reconciling equality to difference: Caring (f)or justice for people with disabilities. Hypatia 10 (1): 30-55.

Silvers, Anita. 2001. Agency, dependency, and disability. In The encyclopedia of ethics, ed. Lawrence Becker and Charlotte Becker. New York: Routledge.

Simplican, Stacy Clifford. 2015. Care, disability, and violence: Theorizing complex dependency in Eva Kittay and Judith Butler. Hypatia 30 (1): 217-33.

Simplican, Stacy Clifford. 2017. Timing problems: When care and violence converge in Stephen King's horror novel Christine. Hypatia 32 (2): 397-414.

Thé, Anne-Mei. 2008. In death's waiting room. Amsterdam: Amsterdam University Press.

Tronto, Joan. 1993. Moral boundaries: A political argument for an ethic of care. New York: Routledge.

Van der Weele, Simon, Femmianne Bredewold, Carlo Leget, and Evelien Tonkens. 2020. What is the problem of dependency? Dependency work reconsidered. Nursing Philosophy, https://doi.org/10.1111/nup. 12327

Van Hove, Geert, Susan L. Gabel, Elisabeth De Schauwer, Kathleen Mortier, Jos Van Loon, Gerrit Loots, Patrick Devlieger, Griet Roets, and Lien Claes. 2012. Resistance and resilience in a life full of professionals and labels: Narrative snapshots of Chris. Intellectual and Developmental Disabilities 50 (5): 426-35.

Vorhaus, Jon. 2007. Disability, dependency and indebtedness? Journal of Philosophy of Education 41 (1): $29-44$. 
Vosman, Frans, Guus Timmerman, and Andries Baart. 2018. Digging into care practices: The confrontation of care ethics with qualitative empirical and theoretical developments in the Low Countries, 2007-17. International Journal of Care and Caring 2 (3): 405-23.

Watson, Nick, Linda McKie, Bill Hughes, Debra Hopkins, and Sue Gregory. 2004. (Inter)dependence, needs and care: The potential for disability and feminist theorists to develop an emancipatory model. Sociology 38 (2): 331-50.

Winance, Myriam. 2010. Care and disability: Practices of experimenting, tinkering with, and arranging people and technical aids. In Care in practice: On tinkering in clinics, homes and farms, ed. Annemarie Mol, Ingunn Moser, and Jeannette Pols. Bielefeld: Transcript Verlag.

Winance, Myriam. 2016. Rethinking disability: Lessons from the past, questions for the future. Contributions and limits of the social model, the sociology of science and technology, and the ethics of care. ALTER: European Journal of Disability Research 10 (2): 99-110.

Winance, Myriam, Aurélie Damamme, and Emmanuelle Fillion. 2015. Thinking the aid and care relationship from the standpoint of disability: Stakes and ambiguities. ALTER: European Journal of Disability Research 9 (3): 163-68.

Simon van der Weele is a $\mathrm{PhD}$ candidate at the University of Humanistic Studies in Utrecht, the Netherlands and visiting scholar at Drew University. His work combines qualitative inquiry and philosophical reflection. He works on care theory, (empirical) ethics, and philosophical anthropology. His dissertation, tentatively titled "The Moral Charge of Dependency: The Ethical Life of Dependency Work in Intellectual Disability Care," studies the significance of 'dependency' as a moral concept for care theory and as a site of ethical tensions in intellectual disability care. S.vanderweele@uvh.nl

Cite this article: van der Weele S (2021). Four Paradigm Cases of Dependency in Care Relations. Hypatia 36, 338-359. https://doi.org/10.1017/hyp.2021.10 